$$
\text { P-ISSN : } 1412 \text { - } 6613 \text { | E-ISSN : } 2527 \text { - } 4570
$$
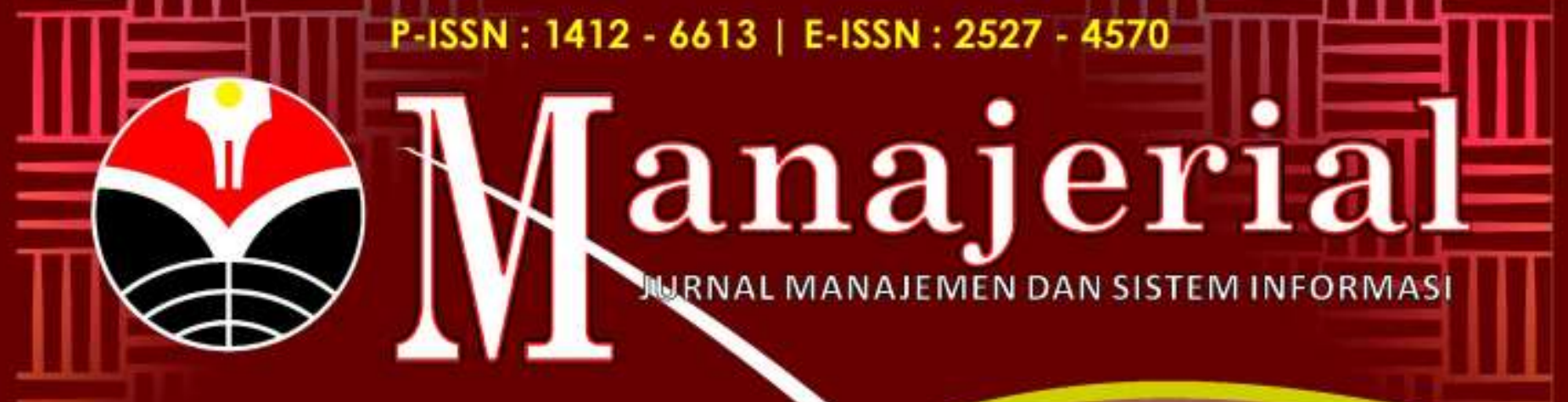

Volume 16, Nomor 1, 2017

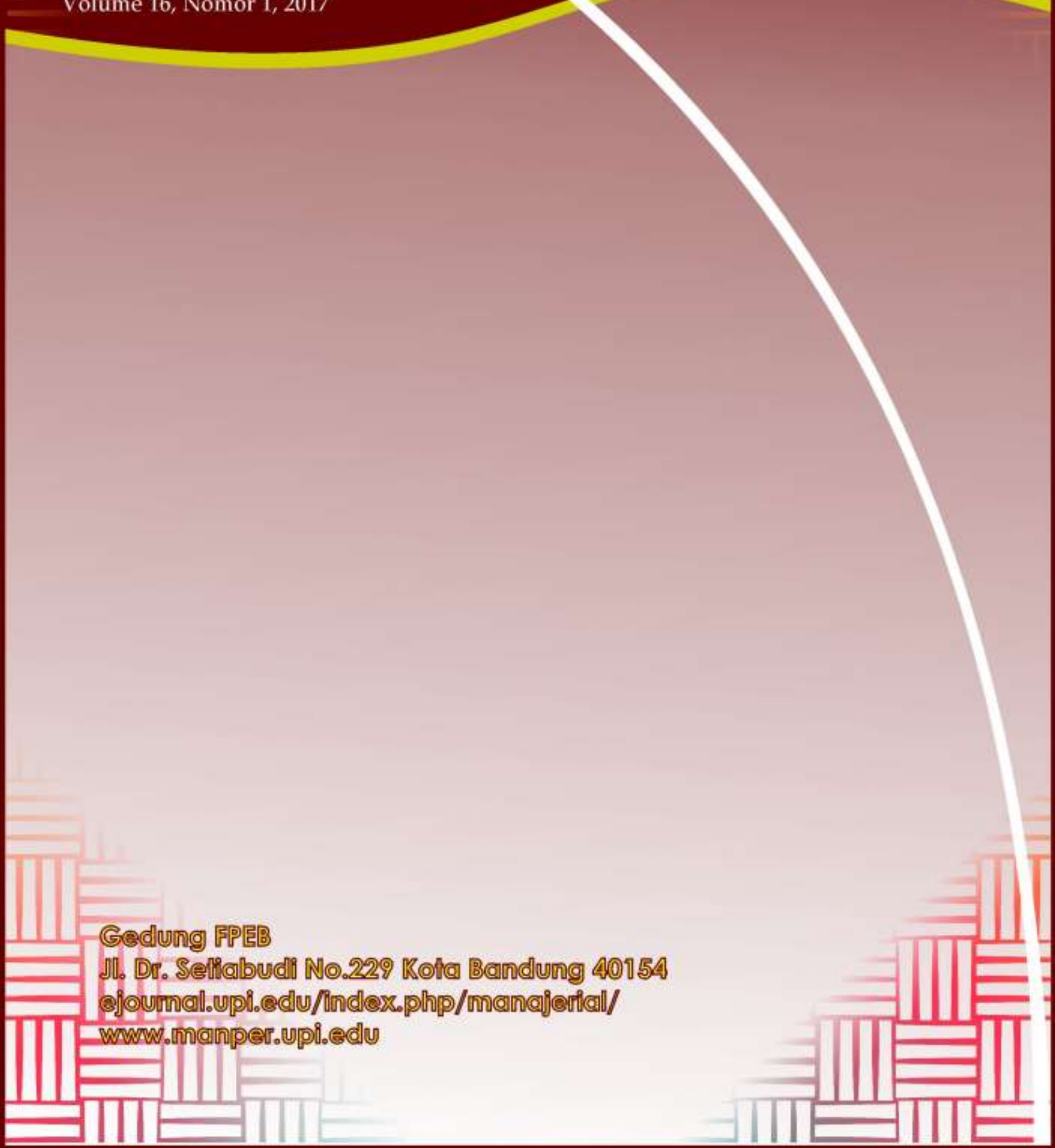


The aim of Jurnal Manajerial is to promote a principled approach to research on management and office management education science-related concerns by encouraging inquiry into the relationship between theoretical and practical studies. The scopes of the topics Journal Manajerial include of current analysis as Management, management information system and office management education. Editorial Team welcome submissions of papers describing researchers, practitioners, regulators, students, and other parties interested in the development of Management, management information system and office management education. Accepts manuscripts of either quantitative research, qualitative research, mix method research, and Research and Development (R\&D) written in either Bahasa Indonesia or English.

\section{PUBLICATION INFORMATION}

Jurnal Manajerial with registered number ISSN 1412-6613 (Print) and ISSN 2527-4570 (Online), is a peer-reviewed journal published twice times a year (January and June) by Program Studi Pendidikan Manajemen Perkantoran Fakultas Pendidikan Ekonomi dan Bisnis Universitas Pendidikan Indonesia. Jurnal Manajerial is intended to be the journal for publishing articles reporting the results of research on Management, management information system and office management education. Jurnal Manajerial cooperation with Asosiasi Sarjana dan Praktisi Administrasi Perkantoran Indonesia (ASPAPI). DOI Prefix 10.17509/manajerial by Crossref

\section{OPEN ACCES POLICY}

The article submitted to this online journal will be peer-reviewed at least 2 (two) reviewers. This journal provides immediate open access to its content on the principle that making research freely available to the public supports a greater global exchange of knowledge. Before going to review process, all manuscripts will be checked that they are free from plagiarism practice using "Turnitin" software. If there an indication of plagiarism, the manuscript will instantly be rejected. Indeks by Google Scholar, Garba Rujukan Digital (Garuda), Indonesia Publishng Index (IPI Indeks) Ristekdikti. 


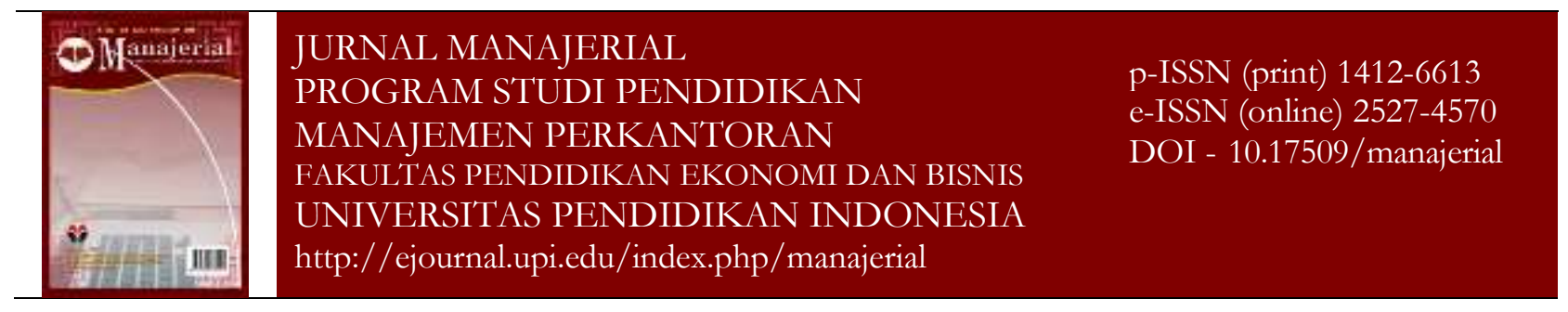

\section{EDITORIAL BOARD}

\section{Editor in Chief}

Prof. Dr. Suwatno, M.Si, [ID SCOPUS : 57191482998], Program Studi Pendidikan Administrasi Perkantoran, Fakultas Pendidikan Ekonomi dan Bisnis, Universitas Pendidikan Indonesia, Indonesia

\section{Vice Chief Editor}

Adman M.Pd, [ID SCOPUS : 57193793639] Program Studi Pendidikan Manajemen Perkantoran, Fakultas Pendidikan Ekonomi dan Bisnis, Universitas Pendidikan Indonesia, Indonesia, Indonesia

\section{Editorial Board}

Dra. Sri Mutmainnah, M.Si, Universitas Negeri Medan, Indonesia

Darma Rika Swaramarinda, S.Pd., M.SE, Universitas Negeri Jakarta

Drs. H. M Jamil Latief, MM., M.Pd, University of Muhammadiyah Prof. Dr. HAMKA (UHAMKA), Indonesia

Meylia Elizabeth, S.Pd., M.S.M, Universitas Negeri Surabaya

Istiadi SE, MM., M.Si, Univeristas Indonesia, Indonesia

Yuhendri L.V, S.Pd., M.Pd, Universitas Negeri Padang, Indonesia

Dr. Edi Suryadi, M.Si, Program Studi Pendidikan Manajemen Perkantoran, Fakultas Pendidikan Ekonomi dan Bisnis, Universitas Pendidikan Indonesia, Indonesia

Dr. Janah Sojanah, M.Si, Program Studi Pendidikan Manajemen Perkantoran, Fakultas Pendidikan Ekonomi dan Bisnis, Universitas Pendidikan Indonesia, Indonesia

Rini Intansari Meilani (Scopus ID: 56493077300), Program Studi Pendidikan Manajemen Perkantoran, Fakultas Pendidikan Ekonomi dan Bisnis, Universitas Pendidikan Indonesia, Indonesia

Drs. Uep Tatang Sontani, M.Si, Program Studi Pendidikan Manajemen Perkantoran, Fakultas Pendidikan Ekonomi dan Bisnis, Universitas Pendidikan Indonesia, Indonesia

Drs. Hendri Winata, M.Si, Program Studi Pendidikan Manajemen Perkantoran, Fakultas Pendidikan Ekonomi dan Bisnis, Universitas Pendidikan Indonesia, Indonesia 
Drs. Alit Sarino, M.Si, Program Studi Pendidikan Manajemen Perkantoran, Fakultas Pendidikan Ekonomi dan Bisnis, Universitas Pendidikan Indonesia, Indonesia

Dr. Sambas Ali Muhidin, M.Si, Program Studi Pendidikan Manajemen Perkantoran, Fakultas Pendidikan Ekonomi dan Bisnis, Universitas Pendidikan Indonesia, Indonesia

Dian Siti Masitoh, SE, MM, Program Studi Pendidikan Manajemen Perkantoran, Fakultas Pendidikan Ekonomi dan Bisnis, Universitas Pendidikan Indonesia, Indonesia

\section{Web and Layout Editor}

Try Hikmawan, S.Pd, Program Studi Pendidikan Manajemen Perkantoran, Fakultas Pendidikan Ekonomi dan Bisnis, Universitas Pendidikan Indonesia, Indonesia

\section{PEER REVIEWER}

Prof. Dr. Haedar Akib, M.Si, Ilmu Administrasi, Fakultas Ilmu Sosial, Universitas Negeri Makasar, Makasar, Indonesia

Prof. Dr. Wiedy Murtini, M.Pd, Pendidikan Administrasi Perkantoran, Fakultas Keguruan dan Ilmu Pendidikan, Universitas Sebelas Maret, Indonesia

Prof. Dr. Tjutju Yuniarsih, SE, M.Pd, Program Studi Pendidikan Manajemen Perkantoran, Fakultas Pendidikan Ekonomi dan Bisnis, Universitas Pendidikan Indonesia, Indonesia, Indonesia

Prof. Dr. Suwatno, M.Si, [ID SCOPUS : 57191482998], Program Studi Pendidikan Manajemen Perkantoran, Fakultas Pendidikan Ekonomi dan Bisnis, Universitas Pendidikan Indonesia, Indonesia, Indonesia

Dr. Madziatul Churiyah, S.Pd., MM, Program Studi Manajemen, Fakultas Ekonomi, Universitas Negeri Malang, Malang

Dr. Ade Rustiyana, M.Si, Program Studi Pendidikan Ekonomi, Fakultas Ekonomi, Universitas Negeri Semarang, Semarang, Indonesia

Dr. Henry Eryanto, MM, Administrasi Perkantoran, Fakultas Ekonomi, Universitas Negeri Jakarta, Jakarta, Indonesia

Dr. Risma Niswati, S.S., M.Si, Universitas Negeri Makasar, Makasar, Indonesia

Dr. Hj. Sri Astuti, M.Pd, University of Muhammadiyah Prof. Dr. HAMKA (UHAMKA), Indonesia

Dr. Armida Silvia, M.Si, Program Studi Pendidikan Ekonomi, Fakultas Ekonomi, Universitas Negeri Padang, Padang

Dr. Grace Soputan, M.Si, Universitas Negeri Manado 


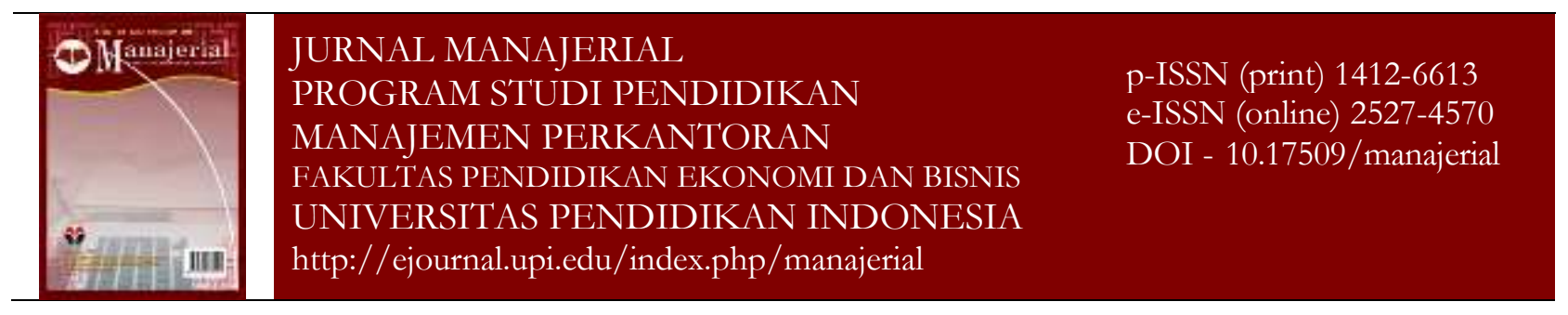

Dr. H. Ade Sobandi, M.Si, M.Pd, Program Studi Pendidikan Manajemen Perkantoran, Fakultas Pendidikan Ekonomi dan Bisnis, Universitas Pendidikan Indonesia, Indonesia, Indonesia

Dr. Budi Santoso, M.Si, Program Studi Pendidikan Manajemen Perkantoran, Fakultas Pendidikan Ekonomi dan Bisnis, Universitas Pendidikan Indonesia, Indonesia, Indonesia

Dr. Rasto, M.Pd, Program Studi Pendidikan Manajemen Perkantoran, Fakultas Pendidikan Ekonomi dan Bisnis, Universitas Pendidikan Indonesia, Indonesia, Indonesia

Dr. Hady Siti Hadijah, M.Si, Program Studi Pendidikan Manajemen Perkantoran, Fakultas Pendidikan Ekonomi dan Bisnis, Universitas Pendidikan Indonesia, Indonesia, Indonesia 
ANALISIS KINERJA GURU (Studi Korelasional Antara Kompetensi Dengan Kinerja 1-12 Guru) Suku Dinas Pendidikan Dasar Kota Administrasi Jakarta Timur D.M. Dharmawati

PERANAN PROGRAM CSR PERBANKAN DALAM MENINGKATKAN 13-34 KESEJAHTERAAN MASYARAKAT DI KABUPATEN KARAWANG

Dedi Sudrajat, Dian Hakip Nurdiansyah

PENGARUH GOOD CORPORATE GOVERNANCE TERHADAP KINERJA DAN 35-45 NILAI PERUSAHAAN (STUDI PADA PERUSAHAAN YANG TERINDEKS OLEH CGPI)

Maria Eva Sulastri, Dian Hakip Nurdiansyah

PENGUASAAN KOMPETENSI PEDAGOGIK GURU PENGARUHNYA TERHADAP KOMPETENSI SIKAP KEWIRAUSAHAAN SISWA (STUDI KASUS PADA PEMBELAJARAN MATA PELAJARAN KEWIRAUSAHAAN)

Endang Supardi, Janah Sojanah, A. Adman

PENGARUH SISTEM MUTASI PEGAWAI BAGIAN MERIT SYSTEM TERHADAP PRESTASI KERJA DI BADAN KEPEGAWAIAN DAN DIKLAT (BKD) KOTA CILEGON

Anton Aliyana, Endang Supardi, A. Adman

PENINGKATAN KINERJA KARYAWAN BGG GOLF AND RESORT JATINANGOR 133-148 MELALUI PENDIDIKAN DAN PELATIHAN KARYAWAN

B. Lena Nuryanti S, Ari Pebrianto

PENERAPAN ORGANIZATIONAL CITIZENSHIP BEHAVIOR DOSEN DI STIE 149-162 BINA BANGSA

Sigit Auliana, Iis Nurasiah

DAMPAK CARA BELAJAR DAN FASILITAS BELAJAR DALAM MENINGKATAN 163-172 PRESTASI BELAJAR SISWA SEKOLAH MENENGAH KEJURUAN

Putri Siti Febriani, Alit Sarino

PENGARUH INSENTIF TERHADAP DISIPLIN KERJA PEGAWAI DINAS 173-186 TENAGA KERJA KABUPATEN BANDUNG

Rizca Amalia, A. Adman

KNOWLEDGE ENTREPRENEURSHIP CONTRIBUTION AND SELF EFFICACY 187-195 TO IMPROVE CREATIVITY STUDENT

K. Kurjono 